\title{
A ANTITESE EM ALGUMAS PEÇAS DE MONTHERLANT
}

\section{Célia Berrettini}

\begin{abstract}
Et que je vive toutes les vies, toutes les diversités et toutes les contradictions du monde, avec intensité et détachement

Les Olympiques.
\end{abstract}

Contradições. É o signo sob o qual se coloca Montherlant, na sua vida particular. Notaram-no sempre os críticos; sublinhou-o Montherlant. Tendo, reiteradamente, declarado sua indiferença em relação à opinião dos leitores, recheia sua obra de notas, explicações, antecipando censuras, e a elas respondendo, quando não as incorpora às próprias observações; tendo desdenhado honrarias, nem por isso deixa de ser oficial da Légion d'Honneur e de receber distinções acadêmicas; tendo atacado, em público, o ensino do Colégio em que estudou, depois preside a solenidade de entrega de prêmios; tendo recusado o epíteto de escritor católico, aceita-o em seguida, tranqüilamente; tendo feito um justo elogio do civismo, dele se esquece ao reivindicar o direito de viver na solidão, longe dos homens; tendo ilustrado a mais rígida sensibilidade católica, passa para a ilustração da mais brutal sensualidade, indo "de la tendresse à la grossièreté, de la légèreté au sérieux, de la pudeur au cynisme" (1); tendo exprimido seu amor pelos touros, mata-os nas touradas; tendo combatido, voluntariamente, na guerra em 1916, presta, no entanto, homenagem ao inimigo; tendo-se indignado contra a França que, em 1938, não declara guerra à Alemanha, faz depois a esta "le salut de l'épée"; pertencendo a um clube de futebol, não hesita em jogar na equipe rival; estando na Āfrica, compõe o romance La.Rose de Sable, cujo objeto é, em primeiro lugar, o protesto contra os métodos da colonização, mas não o publica por escrúpulos patrióticos. Isto faz que um crítico, em 1950, diga: "On peut tout attendre de Montherlant, le meilleur comme le pire", (2) parodiando talvez a pintura

(1) - Pierre de Boisdeffre, Métamorphose de la Littérature, Verviers (Belgique), Marabout Université, 1973, p. 319.

(2) - Pierre de Boisdeffre, op. cit., p. 319 
de Ferrante, de La Reine Morte "Bien meilleur et bien pire. Car j'ai été bien meilleur et bien pire que le monde ne le peut savoir"

Nele coincidem o ateísmo e a religião, o espírito de pugna e o respeito do inimigo, "le héros et le sage" (3) O desfilar de suas contradições, as obras que publica em ocasião inoportuna, e mesmo sabendo que lhe atrairão vigorosos ataques - o que origina a obra crítica Montherlant Bourreau de Soi-même - (4) e as que voluntariamente não publica em ocasião oportuna, e mesmo sabendo que the atrairiam entusiásticos aplausos, todas estas contradições são apontadas pelos críticos, entre os quais pode ser citado Henri Perruchot. Desafio de Montherlant? Não, pela explicação que apresenta, altivamente:

Dès mon second livre, Le Songe, mon parti était pris de m'accepter entièrement en tant qu'homme et en tant qu'écrivain, de ne craindre jamais d'exprimer tout ce que je ressentais, même quand cette expression pourrait m'être comptée à grief. (5)

E, aceitando-se, ou dizendo aceitar-se inteiramente como homem e como escritor, exprimindo tudo de si e da vida, expõe sua doutrina à qual dá o nome de Sincretismo e Alternância. Doutrina elaborada e exposta para justificar e apoiar suas contradições? Ou é ele a ilustração de sua doutrina? Preferimos apenas constatar que, já em 1923, escrevia:

Bonheur, souffrance, candeur, souillure, sagesse, folie, tout m'appartient et je veux tout avoir, car tout m'est bon, si rien ne me l'est assez. Et que je vive toutes les vies, toutes les diversités et toutes les contradictions $d u$ monde, avec intensité et détachement; et que cela soit, puisque je le peux. Tout pouvoir pour tout vivre, tout vivre pour tout connaître, tout connaître pour tout comprendre, tour comprendre pour tout exprimer. (6) (O grifo é nosso).

E a exaltação da posse dos elementos mais diversos e opostos, a apologia do total, de todas as diversidades e contradições: $O$ Sincretismo, doutrina que seria desenvolvida alguns anos mais tarde (1926), especialmente no ensaio "Syncrétisme et Alternance", contido em Aux Fontaines du Désir, (7) além dos ensaios de Service

(3) - Henri Perruchot, Montherlant. Paris, Gallimard, 1959, p. 75.

(4) - Michel de Saint-Pierre, Montherlant Bourreau de Soi-même, Paris, Gallimard, 1949

(5) - Montherlant vous parle, disco "Festival".

(6) - Les Olympiques. Romans et Oeuvres de Fiction non Théâtrales. Paris, Gallimard, 1959 , p. 309

(7) - Aux Fontaines du Désir. In Essais, pp. 231-334. 
Inutile, (8) e I'Equinoxe de Septembre. (9) Mas essa idéia do "tudo viver", "tudo conservar" já estava expressa naquelas páginas que nos parecem essenciais para o conhecimento das ambivalências montherlantianas, e que, por isso, transcrevemos:

La grande affaire n'est pas de renoncer, et qu'on ne ricane pas quand j'ajoute: ce serait trop facile. La grande affaire est de connaître le principe qui doit dominer, de le maintenir, et, autour, de garder tout en composant tout (.) Non, ne cédons rien. Elle n'a pas cessé de faire son fruit, la vieille doctrine de l'union des contraires, formulée par Héraclite, par Hippocrate, que dis-je! par tous les Pères de la pensée grecque. La belle vie tient toujours au tempérament des forces opposées (.. ).

Numa rica acumulação de antíteses, explana e defende Montherlant sua doutrina, feita de "sincretismo", mas também de "alternância", diante da impossibilidade de tudo viver no mesmo instante, da carência humana do dom da ubiqüidade. É assim que prossegue:

La raison en est simple: parce que là est l'exemple de la nature. La nature alterne en elle-même le jour et la nuit, le chaud et le froid, la pluie et la sécheresse, la sérénité et la tempête; et dans les corps la diète et la nourriture, le mouvement et le sommeil: et l'on ne dit pas pour cela que la nature est incohérente ni que sa variété est la confusion.

Tal como a natureza, recusa-se a abdicar do que quer que seja, pretendendo a "unidade total", fundir as pretensas antinomias:

Comme elle, je me refuse à choisir, je veux entrer plus avant dans cette loi universelle du rythme et dans ce jeu divin des compensations; traduisons cela dans la langue de mon siècle: je veux toucher de tous les côtés.

Une âme saine, ayant ce fond de simplicité qui caractérise et permet les choses grandes, sera toujours assez flexible, assez abondante et assez vigoureuse pour fondre joyeusement dans une unité supérieure la plupart de ces prétendues antinomies (. .) (10) (O grifo é nosso)

Pretender unir elementos contrários não é invenção montherlantiana. Obras e obras falaram da riqueza das oposições naturais: a noite sucedendo-se ao dia; a primavera seguindo-se ao inverno; as chuvas seguindo-se às secas. Alternâncias da natureza às quais cor-

(8) - Service Inutile. In Essais, pp. 571-735

(9) - L'Equinoxe de Septembre. In Essais, pp. 743-849.

(10) - Les Olympiques, pp. 308-309. 
respondem as do espírito humano. Ilustres filósofos, como Heráclito - que Montherlant aqui cita — já sonhava com a famosa unidade, princípio da unidade universal, falando da "lógica das contradições"; Nietzsche clamava seu reconhecimento para com "Deus, o diabo, a ovelha e o verme que em nós se ocultam" (foi Montherlant um grande leitor nietzchiano) E não pequena seria a lista dos que pretenderam tal unidade. Ora, Montherlant, o "anti-système" como o qualifica Henri Perruchot, deu aparência de sistema a um estado que lhe é, por assim dizer, fisiológico (11)

Consiste em reconhecer: opostas .

A existência no homem de tendências diferentes e mesmo

b - A necessidade de conservá-las, de vivê-las, todas, sem nenhuma renúncia.

c - A impossibilidade de satisfazer a todas, no mesmo momento, o que leva à prática da alternância .

Embora todas as tendências apareçam, isto só é possível mediante o "tour à tour", expressão tão usada por Costals, o protagonista do romance Les Jeunes Filles (1936): "Il y a en moi toutes les saisons, tour à tour je suis un cosmos qui tourne et expose au soleil les points différents de sa surface, tour à tour! Toujours tour à tour!" (12)

Mas não é mais do que um eco ampliado das palavras de Montherlant, em Coups de Soleil, obra publicada em 1950, mas que contém textos compostos de 1925 a 1930, entre os quais "Syncrétisme et alternance dans l'âme espagnole" repleto de citações de Maurice Barrès ( $D u$ Sang), mas, sobretudo, do admirado Unamuno (Essence de l'Espagne, que corresponde a En torno al casticismo), de quem foi leitor assíduo. Diz Montherlant nesta pequena antologia do que é o "espanhol": "J'allume tour à tour chaque partie de moi-même, mettant durant ce temps les autres en veilleuse" (13)

Este pensamento foi retomado, não uma, mas muitas vezes, em diferentes obras, não constituindo novidade para aqueles que se aproximaram não só da obra ensaística de Montherlant - ensaios, carnets —, mas também dos seus romances e notas de teatro.

A contradição ou o caráter antitético é, pois, característica de Montherlant. Mas vejamos a oposição nos diálogos de algumas pe-

(11) - Henri Perruchot. op. cit.. p. 68.

(12) - Les jeunes filles. In Romans et Oeuvres de Fiction non Théatrales. p. 1.140

(13) Coups de Soleil, Paris La Palatine, 1950 p. 137 
ças de Montherlant, a antítese, este recurso estilístico de todas as épocas.

Existente na poesia popular, se torna mais acentuada "en las escuelas más cortesanas y cultas; arrastrada de los Cancioneros y del Petrarquismo a la segunda mitad del siglo XVI va a tener un extraordinario desarrollo en el conceptismo y el gongorismo del siglo XVII", continuando a ser empregada até hoje (14)

Realmente, este uso das antíteses, "juego intelectual" que fazia as delícias dos conceptistas, com sua "tendencia hacia los contrastes sin solución, hacia lo paradójico", (15) não é, como se sabe, prerrogativa apenas barroca; os românticos delas também fizeram uso, e muito, bastando recordar Hugo, na sua bem conhecida afirmação: "La véritable poésie, la poésie complète, est la synthèse des contraires." (16) E usam-na, ainda, os escritores contemporâneos, assim exprimindo a dualidade dos sentimentos.

Encontrável em tantos poetas, romancistas e dramaturgos, a antítese não poderia deixar de ser uma característica do estilo de Montherlant que teve, entre seus mais ilustres predecessores, Racine, que ele tanto admirou, com seus oxímoros "perfide bonté", "faveurs meurtrières", "orgueilleuse faiblesse", (17) e com seus paradóxicos versos:

"Présente, je vous fuis; absente, je vous trouve." (18)

"Toujours prête à partir, et demeurant toujours." (19)

"Dans une longue enfance ils l'auraient fait vieillir." (20)

Versos reveladores de conflito e recordados por Helmut Hatzfeld, nos seus Estudios sobre el Barroco; (21) mas também, mais próximo a ele, Hugo, igualmente admirado, com os seus antitéticos versos, de Contemplations:

(14) - Dámaso Alonso. Poeta Española. Madrid, Gredos, 1952, pp. 288

(15) - Leo Spitzer, "El conceptismo interior de Pedro Salinas", Revista Hispánica Moderna, New York, 1941, VII, pp. 63-68.

(16) - Victor Hugo, Préface de "Cromwell" Paris, Garnier-Flammarion, 1968, p. 7 .

(17) - Henri Brémond, Racine et Valéry, Paris, Grasset, 1930. Nesta, cita o autor uma lista de oximoros racinianos.

(18) - Phèdre, v 542 .

(19) - Andromaque, v. 131.

(20) - Britannicus, v. 190.

(21) - Helmut Hetzfeld, Estudios sobre el Barroco, Madrid, Gredos, 1966, p. 153. Obra por nós traduzida e será publicada pela Ed. Perspectiva. 
"C'est d'avoir en moi, misérable,

De la fange et du firmament,
\end{abstract}

D'être un ciel et un tombeau."

Versos expressivos de seu dilaceramento entre terra e céu, vida e morte, enfim, de sua disposição ambivalente, conflituosa, estudada entre outros por Charles Baudoin, sob o aspecto psicanalítico. (22)

Sendo a oposição o eixo das peças de Montherlant, natural seria que as personagens recorressem a antíteses isoladas ou acumuladas em séries de notáveis possibilidades expressivas. E preciso insistir que empregadas por Montherlant em ensaios e romances, mesmo antes, e, ainda, depois do teatro, revela tal persistência uma predileção estilística. Se bem que "en passant", faremos uma incursão pela sua obra não teatral. Em La Relève du Matin, de 1920, coletânea de ensaios que constitui uma espécie de extenso poema que canta sobretudo a glória do colégio católico, encontra-se o oxímoro "une espérance désespérée", que é retomado doze anos mais tarde, em Aux Fontaines du Désir, com o seguinte comentário: "une espérance sans espoir. Ce n'est pas un concetto, c'est la réalité même. Mais où donc ai-je déjà vu cette expression-là. Oui, c'est moi qui l'écrivais (dans La Relève): une espérance désespérée. Et il y a douze ans." (23) E esta antítese não mais o deixaria. (24) No romance Le Songe, de 1922, diz o protagonista Alan de Bricoule, em quem se tem visto uma transposição do autor: "Il est nécessaire que je me repose dans l'action"; (25) e em Le Chaos et la Nuit, romance de publicação relativamente recente, de 1963, diz o protagonista, Celestino, tal um místico espanhol: "Je souffre de ne pas souffrir." (26)

Sendo, porém, o teatro o foco de atenção deste trabalho, passemos a ele, com as suas personagens que estão em eterna situação conflituosa, umas em relação às outras, ou em si mesmas.

Perguntou-se um estudioso se o esquema psicológico determina o verbal ou vice-versa, concluindo que tal questão pertence ao domí-

(22) - Charles Baudoin, Psychanalyse de Victor Hugo, Paris, Armand Colin, 1972.

(23) - Aux Fontaines du Désir, in Essais. p. 319.

(24) - Gustave Cohen, In Pesquisa de Retórica. Petrópolis, Ed. Vozes, 1975, pp. 20-24. Nesta obra, entre outras, é feita a distinção entre o exímoro, contradição marcada pela cópula forte $(C)$, como ser; e a antítese, contradição marcada pela cópula fraca (c), como ter, havendo, pois, um parentesco entre as duas figuras, que apenas diferem pelo grau de cópula.

(25) - Le Songe, Romans et Oeuvres de Fiction non Théâtrales. p. 9.

(26) - Le Chaos et la Nuit, Paris, Gallimard, 1963, p. 89. 
nio da alquimia criadora. Mas o que nos interessa por ora é a oposição nas falas, uma vez que é através delas, e apenas atráves delas, que conhecemos estes seres que passam a existir diante da nós, muito embora tenha o autor, várias vezes, partido da história e se documentado a respeito.

Numerosos são os exemplos; limitar-nos-emos a alguns poucos. Em Fils ile Personne, Marie, ao falar de sua solidão, usa pares de termos em contraste:

"Mieux vaut mourir auprès d'un être enfin, entourée d'affection, comme celle de tes grands-parents, que vivre abandonnée et dédaignée" (p. 231).

Em Le Maítre de Santiago, a fala de D. Alvaro opondo o passado, com suas "grandes choses", ao presente com suas "petites", é digna de ser lembrada:

"On aimait l'or parce qu'il donnait le pouvoir et qu'avec le pouvoir on faisait de grandes choses. Maintenant on aime le pouvoir parce qu'il donne l'or et qu'avec cet or on en fait de petites" (p. 502)

Em Demain il fera jour, quando Marie fala a Gillou do desencontro entre ele e o pai, lança mão da expressiva construção antitética; embora falando de sujeitos diferentes, "um elemento comum está efetivamente presente" (27) Ouçamo-la:

"Toi, tu lui parlais comme s'il avait eu quatorze ans.

Lui, il te parlait comme si tu en avais cinquante ans" (p.574).

Já em Le Cardinal d'Espagne, diz a Rainha ao Cardeal, bem marcando a posição entre ambos, no que diz respeito ao crer-não crer, ao pertencer-não pertencer à vida:

"Comment pouvez-vous croire à ce qui vous entoure, vous qui n'êtes plus de ce qui vous entoure, quand moi je n'y crois pas, qui suis, parait-il, en vie?" (p. 1.145).

$\mathrm{E}$, em la Guerre Civile, o soldado Mancia opõe o jovem e o velho Mancia com sua esperança e desesperança paradoxalmente situadas em sua vida:

"Je parlais mal de l'espérance quand j'étais jeune et avais de quoi espérer. Maintenant que je suis vieux et n'ai plus de motif d'espérer, j'ai fait camarade avec l'espérance" (p. 1.285).

(27) - J. Dubois, Retórica Geral, São Paulo, Cultrix, 1974, p. 191. 
Mas concentremos nossa atenção no vocabulário. Para tal, procedemos ao levantamento do vocabulário com nítida e indiscutível oposição, formando pares de associação em contraste empregados por uma única personagem e na mesma fala; procedemos ainda, de maneira natural e sem lançar mão de moderna terminologia, ao levantamento de certos termos (como "opposer", "opposition", "contredire", "contre") que bem marcam a oposição (vide Anexo I, colocado no final deste capítulo) (*) Computando os resultados na Tabela I, em que estão dispostas as peças por ordem de publicação, notamos:

Le Cardinal d'Espagne é a peça que apresenta o maior número de pares de associação contrastante, além de termos com oposição: 100 , o que equivale à média de mais de um emprego por página (a obra começa à página 1.103 e termina à página 1170 do volume Théâtre) Aliás, a própria epígrafe do Ato I põe em realce o aspecto ambivalente, contraditório, do protagonista:

.. cette phrase si importante de l'Entretien avec $M$. de Saci, où il est dit que M. Singlin voulait donner à Pascal un maître, qui lui enseignât les sciences, et un autre maître, qui lui apprît à les mépriser. Cette phrase me rappelle le cardinal Jiménez, qui portait une robe de bure sous sa pourpre; la bure démentait la pourpre; c'est ce démenti que l'être de sagesse doit porter sans cesse en soi: le démenti que l'homme intérieur donne à l'homme extérieur (p. 1.103)

(*) - Por motivos técnicos, suprimiram-se os Anexos I e II que constam de Ambivalencias no Teatro de Montherlant, tese apresentada no Concurso de Livre-docência - ECA - USP — 1977. 
TABELA - I

PARES DE ASSOCIAÇÃO EM CONTRASTE E VOCABULÁRIO QUE EXPRIME OPOSIÇĀO

$\mathrm{La}$

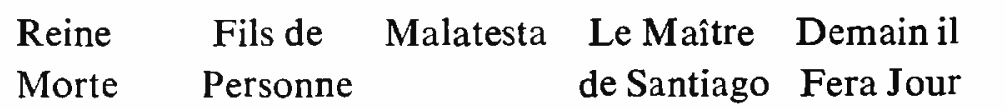

La Ville

dont le

prince

Port-Royal qui fait

La Mort Le Ca:dinal La Gurre

est un le trottoir d'Espagne Civile

Total

95

32

63

49

28

enfant

NEGATIVAS-AFIRMATIVAS e AFIRMATIVAS-NEGATIVAS

29

25

22

12

7

11

25

17

37

38

223

TOTAL 124

57

85

61

35

44

101

71

137

121

836 
Ora, examinando a distribuição dos casos, por personagem, notamos que quem mais os utiliza é o Cardeal:

$$
\text { TABELA - II }
$$

\begin{tabular}{|c|c|c|c|c|c|}
\hline Cardeal & $\cdots \cdots$ & $\cdots$ & $\cdots$ & & \\
\hline Sobrinho & $\ldots$ & $\ldots$ & .. & & . \\
\hline Rainha & .. & .. & $\ldots$ & & \\
\hline Aralo & .. & $\ldots$ & $\ldots$ & . & . \\
\hline Estivel & .. & .. & & & \\
\hline "Demoiselle" & $\ldots$ & & $\cdots$ & ... & \\
\hline Eclesiástico & .. & . & & & \\
\hline Nobre & .. & & $\cdots$ & . & \\
\hline Estrada & .. & & & & \\
\hline $\begin{array}{l}\text { Dama } \\
\text { (Epígrafe) }\end{array}$ & . & & & & \\
\hline
\end{tabular}

Realmente, é o Cardeal a personagem mais antitética, a que mais opõe $o$ que é e o que parece ser, ou o que crê ser Quanto às outras personagens, como a Rainha ou o sobrinho, de maneira geral, usam os termos em contraste, quando se referem ao Cardeal, completando, pois, o seu perfil, ou o próprio.

Em seguida, vem La Reine Morte, que apresenta 95 casos, com a seguinte distribuição:

$$
\text { TABELA - III }
$$

\begin{tabular}{|c|c|c|c|c|}
\hline$\ldots \ldots$ & .. & .. & $\ldots$ & 60 \\
\hline Inès $\quad \ldots$ & . & .. & .. & 13 \\
\hline Pedro $\quad$. & $\ldots$ & $\ldots$ & & 10 \\
\hline Infanta & $\ldots$ & .. & .. & 5 \\
\hline Egas & & & & 4 \\
\hline Alvar $\quad \ldots$ & $\ldots$ & .. & & 2 \\
\hline D. Manoel & $\ldots$ & $\ldots$ & . & 1 \\
\hline TOTAL & .. & $\ldots$ & & 95 \\
\hline
\end{tabular}

O contraditório Rei que brada contra "le noeud de contradictions" nele existente fazia prever tal índice de freqüência, que é realmente elevado em relação aos demais. dos:

Segue-se a peça La Guerre Civile, com 83 casos, assim distribuí- 


\section{$T A B E L A-I V$}

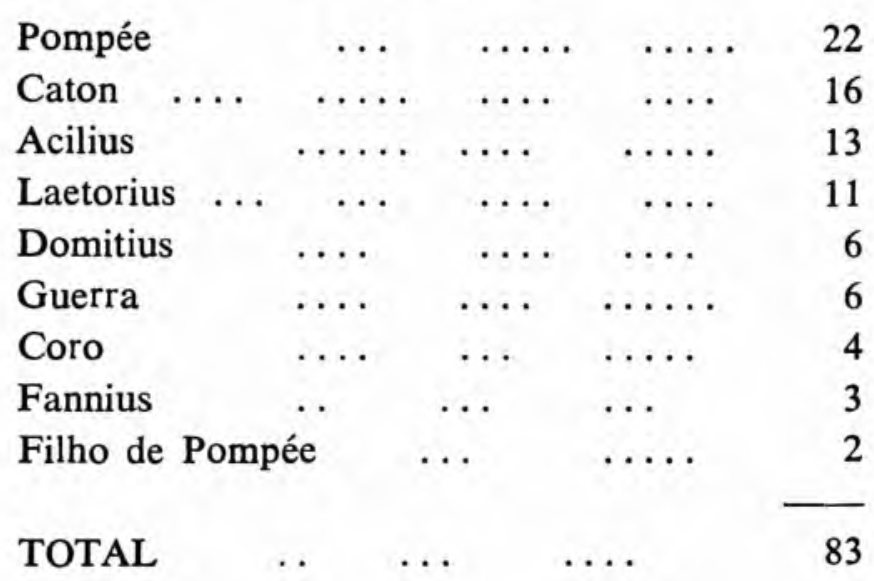

Notamos que os que mais deles fazem uso são Pompée e Caton, ambos em conflito interior, decorrente da situação. Acilius representa a total oposição a Pompée e a tudo o que este simboliza, enquanto Laetorius se opõe a César; e Domitius à situação a que está reduzido, vítima tanto de Pompée quanto de César, e do escravo que não lhe forneceu o veneno. Já a Guerra e o coro, muitas vezes, sublinham a situação conflituosa .

Vem em seguida Port-Royal, com um total de 76 casos, assim distribuídos:

$$
T A B E L A-V
$$

\begin{tabular}{|c|c|c|c|c|}
\hline \multirow{2}{*}{\multicolumn{2}{|c|}{$\begin{array}{l}\text { Irmã Angélique } \\
\text { Irmã Françoise }\end{array}$}} & \multicolumn{2}{|c|}{$\ldots$} & 28 \\
\hline & & . & $\ldots$ & 11 \\
\hline Madre & $\ldots$ & $\ldots$ & . & 7 \\
\hline Irmã Flavie & $\ldots$ & & & 8 \\
\hline Irmã Gabrielle & & $\ldots$ & & 7 \\
\hline Arcebispo & . & & $\ldots$ & 5 \\
\hline Pai de Gabriel & & $\ldots$ & $\ldots$ & 2 \\
\hline Irmã Julie & . & $\ldots$ & $\ldots$ & 2 \\
\hline Irmã Louise & & $\ldots$ & $\ldots$ & 2 \\
\hline Priora & $\ldots$ & $\ldots$ & $\ldots$ & 1 \\
\hline Abadessa & & $\ldots$ & . & 1 \\
\hline Irmã Hélène & $\ldots$ & $\ldots$ & & 1 \\
\hline Uma religiosa & & & & 1 \\
\hline TOTAL & . . & & . & 76 \\
\hline
\end{tabular}

Com efeito, são as duas primeiras as personagens que, além da oposição ao clero e às forças que invadem Port-Royal, maior oposição 
apresentam em seu interior, ainda que de diferentes maneiras: a Irmã Angélique, com suas dúvidas, sendo que ao mesmo tempo que defende a não assinatura do "Formulário", transpõe as "Portes des Ténèbres", enquanto a Irmã Françoise, que antes era indiferente à assinatura, muda de posição e transpõe as "Portes des Lumières" Quanto à Madre, opõe-se tanto à falta de fé da Irmã Angélique, como ao clero que as persegue; a Irmã Flavie, à Irmã Angélique; e Péréfixe, às religiosas, sobretudo, através dos diálogos com a Irmã Angélique e a Irmã Françoise.

Quanto a Malatesta, apresenta 63 casos, com a seguinte distribuição por personagem:

$$
T A B E L A-V I
$$

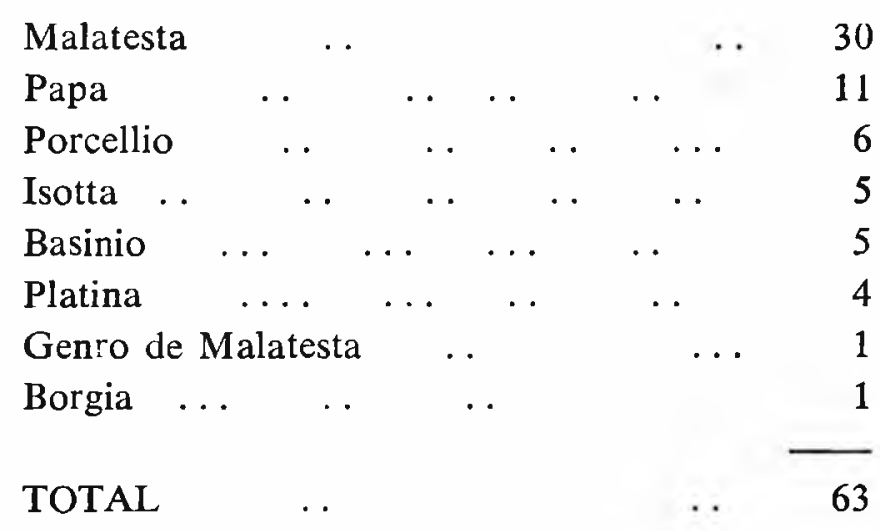

Ao móvel e contraditório Malatesta cabe o maior número de casos, o que é profundamente coerente, inclusive por opor-se ao Papa, no que há reciprocidade, explicando o segundo lugar que este ocupa. Porcellio, com a surda oposição a Malatesta, Basinio e Isotta (que se coloca ao lado do marido, contra o Papa) ocupam os lugares subsequientes.

O mesmo ocorre com o protagonista da peça La Mort qui fait le trottoir, que é, em relação às personagens que o rodeiam, o emissor do maior número de termos em oposição. Vejamos a distribuição por personagens:

$$
T A B E L A-V I I
$$

D. Juan

Comendador

Alcacer .....

Condessa
36

7

5 


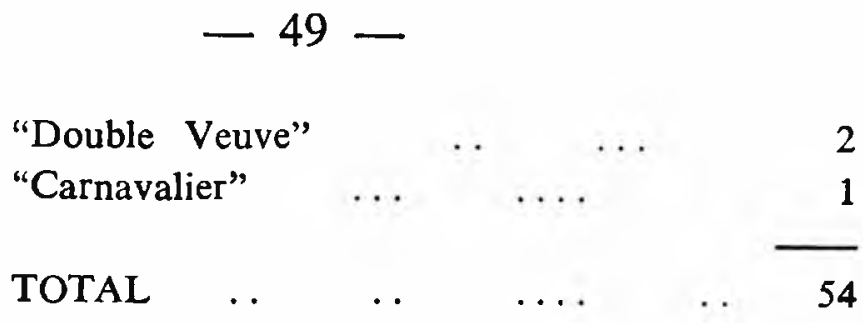

Quanto a Le Maítre de Santiago, notamos também uma grande superioridade do protagonista, no que diz respeito a tal emprego, em comparação com as outras personagens da peça. Assim se distribuem os casos:

$$
\text { TABELA - VIII }
$$

$\begin{array}{lcccr}\text { Álvaro } & \ldots & \ldots & \ldots \ldots & 32 \\ \text { Bernal } & \ldots & \ldots & \ldots & 5 \\ \text { Campanita } & \ldots & \ldots & \ldots & 4 \\ \text { Conde } & \ldots & \ldots & \ldots & 4 \\ \text { Mariana } & \ldots & \ldots & \ldots & 3 \\ \text { Olmeda } & & \ldots & \ldots & 1 \\ & & & & \\ \text { TOTAL } & \ldots & \ldots & \ldots \ldots & 49\end{array}$

E natural tal emprego numa personagem que, como sabemos, está em permanente oposição ao mundo, por suas exigências de grandeza não satisfeitas.

Em La Ville dont le prince est un enfant, é o Abade que manifesta maior predileção pelas oposições, o que é também explicável pela sua atitude em relação a Sevrais e à sua própria situação diante das críticas que recebe do Superior. A distribuição é a seguinte:

$$
T A B E L A-I X
$$

$\begin{array}{lcccr}\text { Abade } & \ldots & \ldots & \ldots & 21 \\ \text { Sevrais } & \ldots & \ldots & \ldots & 5 \\ \text { Habert } & \ldots & \ldots & \ldots & 4 \\ \text { Souplier } & \ldots & \ldots & \ldots & 2 \\ \text { Superior } & \ldots & \ldots & & \ldots \\ & & & & 1 \\ \text { TOTAL } & \ldots & \ldots & \ldots & 33\end{array}$

Vem, em seguida, Fils de Personne, que obedece à expressa intenção do autor no que diz respeito à simplicidade ((pp. 211-5). E Georges que usa os contrastes de maneira predominante, tendo em vista sua oposição a todos e a tudo. Vejamos a distribuição geral: 


$$
T A B E L A-X
$$

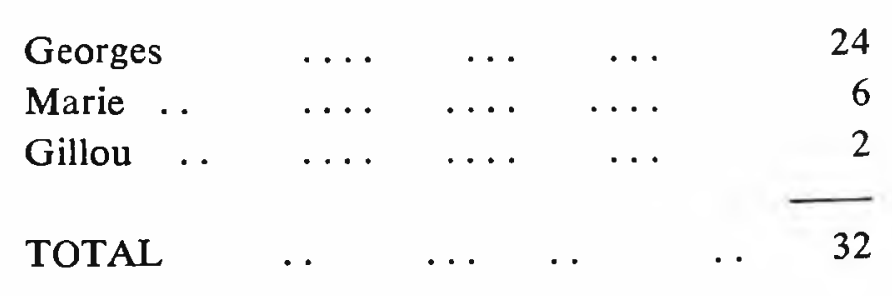

E Demain il fera jour, que, segundo as próprias palavras de Montherlant, também obedece à intenção de maior sobriedade, apresenta um número relativamente baixo de oposição. Apenas 28 casos, assim distribuídos:

$$
T A B E L A-X I
$$

$\begin{array}{lccccrr}\text { Georges } & \ldots & \ldots & \ldots & \ldots & \ldots & 13 \\ \text { Marie } & \ldots & \ldots & \ldots & \ldots & & 11 \\ \text { Gillou } & \ldots & \ldots & \ldots & \ldots & & 4 \\ & & & & & \\ \text { TOTAL } & \ldots & \ldots & \ldots & \ldots & & 28\end{array}$

Como era de prever-se, Georges é a personagem que delas faz maior uso, uma vez que é quem mais se opõe à própria situação e à do mundo.

Impossível encerrarmos estas observações sobre o vocabulário, sem alguma referência à predileção de várias personagens pelas nuvens: estas se formam e se desfazem, surgem e se dissipam, num oposto movimento de construção e destruição, além de mutação. E D. Álvaro que nota "Puisse mon nom être comme ces nuages qu'un peu d'heures efface" (p. 513); é a Rainha que fala ao Cardeal: "Les idées, cela n'est pas sérieux. Ce sont des nuages qui changent de forme et enfin se dissipent" (p. 1.139); é o Cardeal que, sob o impacto da niilista Rainha, afirma: "Le temps ne presse pas quand les nuages se transforment et se défont" (p. 1.150); é o Coro de La Guerre Civile que anuncia que "une armée de cinquante mille hommes s'était dissipée comme se dissipent les nuages" ( $p$. 1.306), sendo que na penúltima peça notável é a persistência do tema como imagem da futilidade da ação humana, que se repete sem cessar, através dos séculos. Esta visão da história do mundo, com os inúteis atos humanos já expressa nos Carnets, é posta em epígrafe no Ato II, quando se enfrentam o Cardeal e a Rainha num acirrado debate sobre a utilidade ou não da ação: "Toute l'histoire du monde est une histoire de nuages qui se construisent, se détruisent, se idissipent, se reconstruisent, 
en des combinaisons différentes - sans plus de signification ni d'importance dans le monde que dans le ciel" ( $\mathrm{p}$. 1.127) (O grifo é nosso).

Além do emprego desses pares de associação em contraste e do vocabulário que exprime oposição, é necessário salientar ainda a predileção de Montherlant pelas frases de construção simétrica ou semi-simétrica, com base em afirmativas e negativas e vice-versa, com combinações, se bem que a oposição nem sempre provenha dessas formas (Vide Anexo II, no final do capítulo) Há, no entanto, a tendência a afirmar e negar ou a negar e afirmar; tendências, pois, opostas.

Transcrevamos, à guisa de exemplo, algumas das falas que apresentam tal tipo de construção, às quais atribuímos fórmulas $\mathrm{N} / \mathrm{A}$ ou $\mathrm{A} / \mathrm{N}$, isto é, Negativa-Afirmativa ou Afirmativa-Negativa, havendo ainda outras combinações que não obedeceram - é preciso notar a nenhuma intenção de análise sintática; é antes uma análise espontânea, ou melhor, catalogação própria, subjetiva, cujo irtuito é apenas o de comprovar a predileção montherlantiana pela Negativa-Afirmativa e vice-versa, e cujos resultados aparecem na mesma Tabela I. Vejamos um exemplo de cada peça:

N/A - "Je ne suis pas un roi de gloire, je suis un roi de douleur" (La Reine Morte, p. 156 - O Rei falando a Inès)

A/N - "Je l'aime et je n'aime pas sa présence" (Fils de Personne, p. 252, Georges a Marie).

$N A / A($ A ) - "Ce n'est pas la neige qui arrête ces messieurs. C'est un autre froid "(Le Maître de Santiago, p. 480, Tia Campanita a Mariana).

$\mathrm{N}-N N / A A \mathrm{AA}-$ "Est-ce que pourtant vous ne voyez pas que je ne le regarde jamais, que jamais mes yeux ne se posent sur son visage, tandis que vous, vous le regardez même à la dérobée, pour le regarder encore un peu plus, comme fait une femme qui veut regarder encore plus son amant?" (Demain il fera jour, p. 565, Georges a Marie).

$\mathrm{A} A$ / et $\mathrm{A} N$ - La haine est douce quand elle peut s'assouvir, et douloureuse quand elle ne le peut pas" (Malatesta, p. 399, Basinio a Porcellio).

A/ouN et A/ou NAN - "Des cinq propositions qui sont ou qui ne sont pas hérétiques, et qui sont ou qui ne sont pas dans Jansénius, il y en a trois dont on ne nous parle jamais " (Port-Royal, p. 868, a Irmă Angélique è Irmã Françoise). 
A mais NA/AAN - "II y a en vous un feu mais ce n'est pas celui dont parle Saint Bernard, c'est un feu qui brûle et qui n'éclaire pas" ( $L a$ Ville dont le Prince est un Enfant, p. 733; Superior ao Abade).

A-AN/ mais NA - "II est pourtant assez notoire que jaccorde quelque fois ce qu'on ne me demande pas, mais que je n'accorde jamais ce qu'on me demande (Le Cardinal d'Espagne, p. 1.115, Cardeal ao Sobrinho).

$A A / N N$ - "Ce que je suis.mourra, non ce que je ne suis pas" (La Mort qui fait le trottoir, p. 1.067, D. Juan a Alcacer).

$\mathrm{AA} A /$ et (A) AN - "Il y a un temps où les louanges vous fortifient parce qu'on $\mathrm{y}$ croit, et un temps où elles vous font mal, parce qu'on n'y croit plus" (La Guerre Civile, p. 1.296, Pompée ao filho)

Tais exemplos extraídos das diferentes peças - que apresentam, aliás, outros - parecem reveladores da tendência montherlantiana pela oposição.

Mas vejamos como tal tipo de construção se distribui por personagens em cada peça, sendo que, quando surge nas falas entre duas personagens e não na fala de uma única, computamos $1 / 2$ para cada uma. Em ordem decrescente, temos:

La Guerre Civile apresenta 38 casos, com a seguinte distribuição:

$$
T A B E L A-X I I
$$

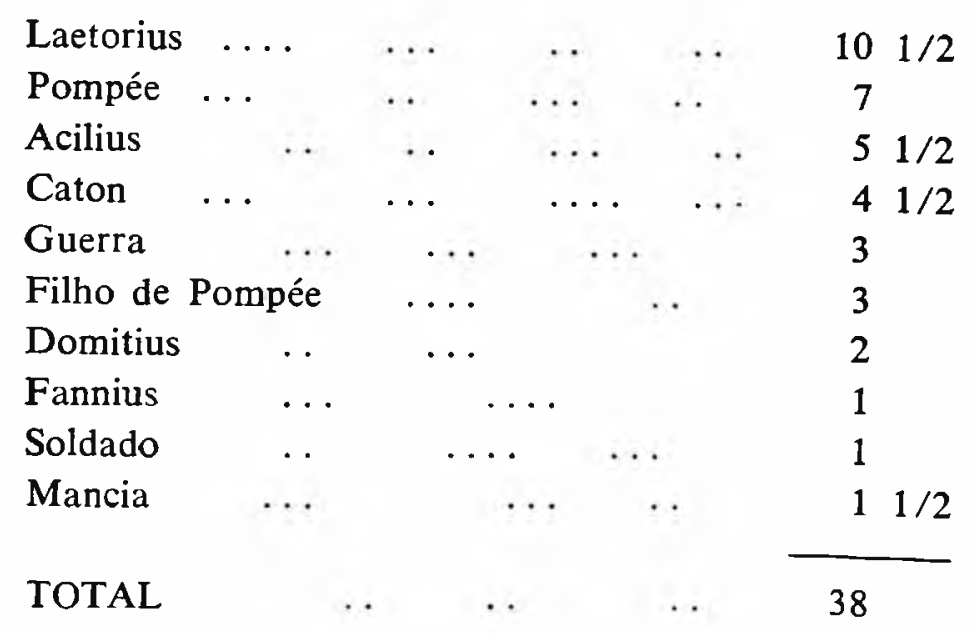


Como vemos, é o sinuoso Laetorius que mais emprega este tipo de construção, sendo seguido pelo indeciso Pompée.

Le C'ardinal d'Espagne ocupa o segundo lugar, com pequena diferença: 37 Notamos que são o dilacerado Cardeal e a lúcidalouca Rainha os que mais empregam tal tipo de construção, seguidos pelo contraditório sobrinho do eclesiástico:

$$
T A B E L A-X I I I
$$

$\begin{array}{lcccccc}\text { Cardeal } & & \ldots & \ldots \ldots & & 14 \\ \text { Rainha } & . & \ldots & \ldots & \ldots & 11 & 1 / 2 \\ \text { Sobrinho } & & \ldots & \ldots & \ldots & 6 & 1 / 2 \\ \text { Estivel } & \ldots & \ldots & \ldots \ldots & & 2 & \\ \text { Aralo } & \ldots & \ldots & \ldots & \ldots & 2 \\ \text { Nobre } & \ldots & \ldots & \ldots \ldots & \ldots & 1 \\ & & & & & \\ \text { TOTAL } & \ldots & \ldots & & \ldots & \ldots & 37\end{array}$

La Reine Morte apresenta 29 casos, assim distribuídos:

$$
T A B E L A-X I V
$$

$\begin{array}{lcccr}\text { Rei } & \ldots & & \ldots & 16 \\ \text { Pedro } & & \ldots & & 5 \\ \text { Inès } & \ldots & \ldots & \ldots & 4 \\ \text { Infanta } & \ldots & \ldots & \ldots \ldots & 3 \\ \text { Egas } & \ldots & \ldots & \ldots & 1 \\ & & & & -29\end{array}$

Como vemos, é o contraditório Rei que mais faz uso das negativas-afirmativas, seguido por Pedro e Inès .

Quanto a Port-Royal e Fils de Personne apresentam o mesmo número de casos. Na primeira, encontramos a seguinte distribuição:

$$
T A B E L A-X V
$$

Irmã Françoise

Irmã Angélique

Irmã Gabrielle

Madre

Arcebispo

Abadessa

Visitante

TOTAL 
Há, pois, a superioridade de ambas protagonistas quanto a esse tipo de emprego.

Quanto a Fils de Personne, apresenta a seguinte distribuição por personagens:

$$
T A B E L A-X V I
$$

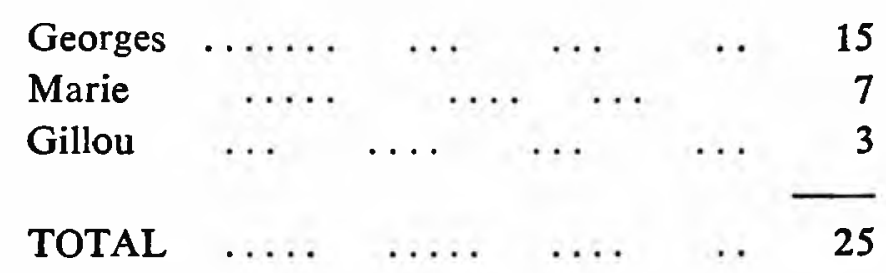

Georges, nesta peça como na outra que a completa, é quem mais usa este tipo negativo-afirmativo ou afirmativo-negativo.

Em Malatesta, há a seguinte distribuição, com o mutável Malatesta em primeiro lugar, seguido pelo traidor Porcellio:

$$
T A B E L A-X V I I
$$

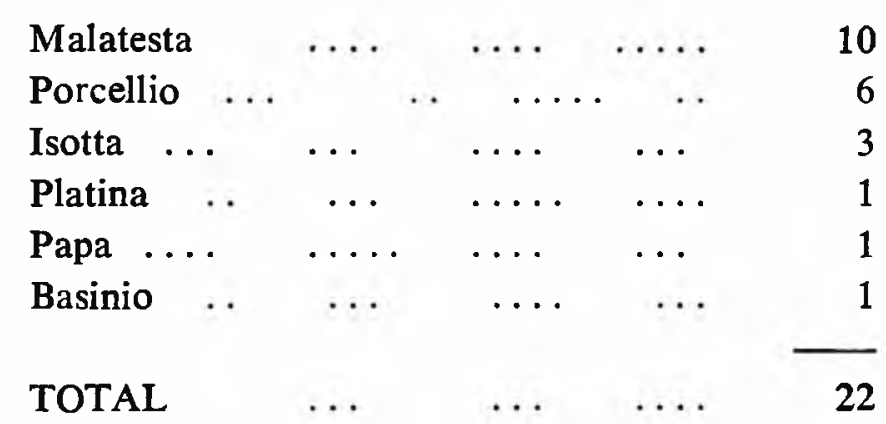

Quanto a La mort qui fait le trottoir apresenta em primeiro lugar o móvel D Juan negando e afirmando ou afirmando e negando:

$$
\text { TABELA - XVIII }
$$

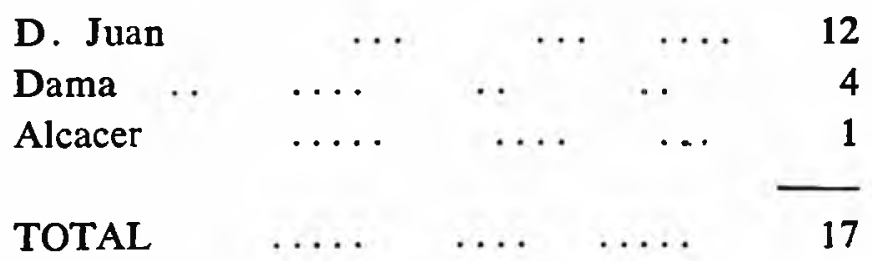

Le Maître de Santi ${ }^{a}$ go, com poucos casos, apresenta os dois opositores, D. Bernal e D Álvaro, nos primeiros lugares. E o Conde, por seu papel na peça, vai usar a negativa-afirmativa para persuadir D. Ālvaro a partir 


\begin{tabular}{|c|c|c|c|c|c|}
\hline & $T A$ & $E L A$ & $-X I$ & & \\
\hline Bernal & $\ldots$ & $\ldots$ & $\ldots$ & $\ldots$ & 4 \\
\hline Ålvaro & $\ldots$ & $\ldots$ & $\ldots$ & $\ldots$ & $31 / 2$ \\
\hline Mariana & $\ldots$ & . & . & $\ldots$ & 2 \\
\hline Conde & $\ldots$ & $\ldots$ & $\ldots$ & $\ldots$ & $11 / 2$ \\
\hline Campanita & $\ldots$ & . & $\ldots$ & $\ldots$ & 1 \\
\hline TOTAL & . & & $\ldots$ & $\ldots$ & 12 \\
\hline
\end{tabular}

Em La Ville dont le prince est un enfant é o conflituoso Abade que mais faz uso de tal tipo de fala, como vemos na:

$$
T A B E L A-X X
$$

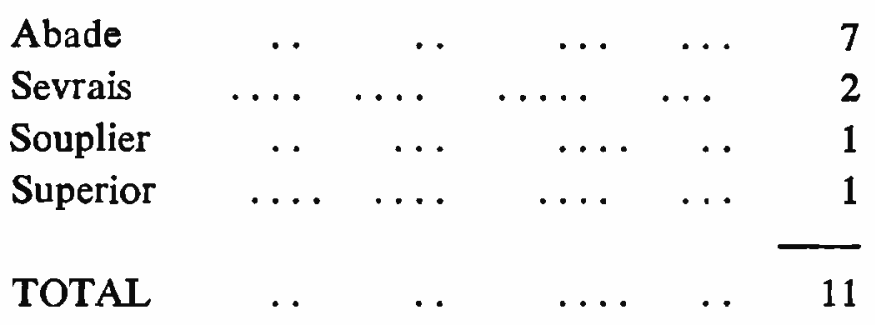

E Demain il fera jour, como Fils de Personne, apresenta Georges em primeiro lugar:

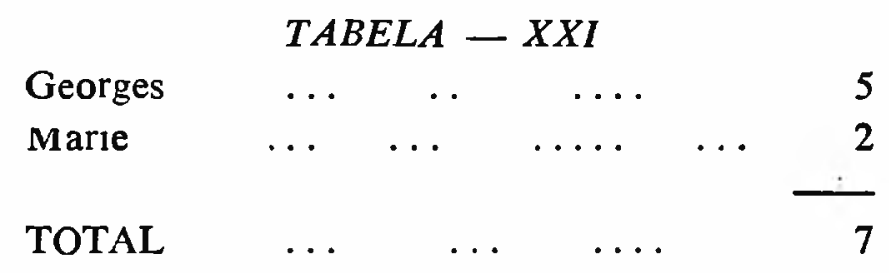

Examinando a Tabela $I$, com a soma dos resultados gerais, notamos que Le Cardinal d'Espagne, La Reine Morte e La Guerre Civile, as últimas e a primeira obra-prima, são as que apresentam superioridade quanto ao tipo de vocabulário contrastante e de falas afirmativas-negativas ou negativas-afirmativas. A permanência, pois, de uma característica barroca, sendo Montherlant "el hombre de barroco," (28) não apenas pelos temas de sua obra: a desenganada atitude diante da vida; o angustiado sentimento em face da morte e a aguda atração do Nada. 